\title{
Near-Death and Out-of-Body Experiences in the Blind: A Study of Apparent Eyeless Vision
}

\author{
Kenneth Ring, Ph.D. \\ Sharon Cooper, M.A. \\ University of Connecticut
}

\begin{abstract}
This article reports the results of an investigation into neardeath and out-of-body experiences in 31 blind respondents. The study sought to address three main questions: (1) whether blind individuals have neardeath experiences (NDEs) and, if so, whether they are the same as or different from those of sighted persons; (2) whether blind persons ever claim to see during NDEs and out-of-body experiences (OBEs); and (3) if such claims are made, whether they can ever be corroborated by reference to independent evidence. Our findings revealed that blind persons, including those blind from birth, do report classic NDEs of the kind common to sighted persons; that the great preponderance of blind persons claim to see during NDEs and OBEs; and that occasionally claims of visually-based knowledge that could not have been obtained by normal means can be independently corroborated. We present and evaluate various explanations of these findings before arriving at an interpretation based on the concept of transcendental awareness.
\end{abstract}

\footnotetext{
Kenneth Ring, Ph.D., is Professor Emeritus of Psychology at the University of Connecticut, where Sharon Cooper, M.A., was Research Assistant at the time of this study. This study was funded in part by the Institute of Noetic Sciences, to which the authors express their deep thanks for its support. They also acknowledge their deep thanks to Lucienne Levy for her invaluable help in connection with this research. The authors are also indebted to the following organizations for their collaboration in this study: the American Council of the Blind; the American Foundation for the Blind; Blindskills, Incorporated; the Massachusetts Association for the Blind; the Massachusetts Commission for the Blind; the National Braille Press; the National Federation for the Blind; the National Federation for the Blind in Connecticut; Newsreel Incorporated; the Theosophical Book Association for the Blind; and the Ziegler Magazine for the Blind. Reprint requests should be addressed to Dr. Ring at 19A Stadium Way, Kentfield, CA 94904.
} 
This life's dim windows of the soul

Distorts the heavens from pole to pole

And leads you to believe a lie

When you see with, not thro', the eye.

William Blake, "The Everlasting Gospel" (circa 1818)

The question of whether blind individuals can actually see during out-of-body experiences (OBEs) while close to death has long intrigued researchers in the field of near-death studies. In part, the idea that this seemingly impossible event could really occur has been fueled by occasional anecdotal reports by prominent researchers (e.g., Kübler-Ross, 1983; Moody and Perry, 1988) that they have come across such cases in the course of their investigations. Lesser known physicians interested in near-death experiences (NDEs), such as Fred Schoonmaker of Denver's St. Luke's Hospital, have also mentioned that they have heard such claims from their blind patients (Schoonmaker, personal communication, 1981). Similarly, another physician, Larry Dossey, opened his book Recovering the Soul (1989) with the dramatic case of a woman named Sarah, blind from birth, who had detailed visual perception during surgery when her heart had stopped.

As a result of these accounts in the literature, other researchers and writers who have taken an interest in NDEs have used such cases to make a powerful argument on behalf of the authenticity of near-death phenomena (Anderson, 1980; Habermas and Moreland, 1992; Iverson, 1992; Wilson, 1987; Woodward, 1976). Representative of this view is a passage in a recent book by a leading figure in transpersonal psychology, the psychiatrist Stanislav Grof:

There are . . . reported cases where individuals who were blind because of a medically confirmed organic damage to their optical system could at the time of clinical death see the environment. . . . Occurrences of this kind, unlike most of the other aspects of neardeath phenomena, can be subjected to objective verification. They thus represent the most convincing proof that what happens in neardeath experiences is more than the hallucinatory phantasmagoria of physiologically impaired brains. (1994, p. 31)

Yet there is reason, we think, not to leap too quickly to the conclusion that the evidence supporting visual perception in the blind is as solid as Grof's statement would imply. In fact, when one begins to look into the basis for these claims, they appear to dissolve into the mists of hearsay, unsubstantiated anecdote and other dead ends-and even, in one case, outright fabrication. For example, Kübler-Ross and 
Schoonmaker have never documented the cases they have mentioned or published any details concerning them. Similarly, when one of us (K. R.) pressed Raymond Moody for further particulars about the blind person he described in one of his books, he could only remember that he had heard that account on an audio cassette provided to him by an elderly physician, but he no longer had the tape and could not recall the physician's name ( $R$. Moody, personal communication, 1992). And the compelling case of Sarah, so vividly portrayed by Dossey, turned out, as he confessed in a letter to K. R., to be a complete fiction, though Dossey justified it on the grounds that such cases seemed to be implied by the literature on NDEs (L. Dossey, personal communication, 1990). Indeed, Susan Blackmore (1993) has recently reviewed all this evidence and concluded that none of it holds up to scrutiny. In short, according to her, there is no convincing evidence of visual perception in the blind during NDEs, much less documented support for veridical perception (Blackmore, 1993).

Nevertheless, while there may be reason to concur with Blackmore's assessment, there was at least one study that did attempt to inquire whether any evidence for this proposition could be gathered by systematically interviewing a sample of blind respondents. In that investigation, Harvey Irwin (1987) had field workers survey a sample of 21 blind persons in Australia. The focus of Irwin's project was to see whether any such persons had had an OBE and, if so, to get an account of it. Among his 21 respondents, three persons did indeed report having had an OBE. Unfortunately, as Irwin ruefully had to admit, all of these persons had either some residual or peripheral vision, so they did not in the end constitute anything like a stringent cohort in terms of which to evaluate the hypothesis that the blind can see. Irwin's own conclusion at the time was that neither his own survey nor the work of anyone else had demonstrated that persons blind from birth even have OBEs, and therefore no evidence existed that such individuals could see under such circumstances. "It now remains," he wrote, "for further surveys to locate an OBE in a congenitally totally blind person" (Irwin, 1987, p. 57).

This is precisely what we have attempted to do in this study. In what follows we describe the results of a research project in which an effort was made to locate and interview blind persons, including those blind from birth, who believed they had undergone either an NDE or an OBE not related to any near-death incident. The principal underlying aim of this study, however, will already be apparent: we were concerned to determine whether in fact any reliable evidence 
could be educed from such a sample that the blind really do see under such conditions.

The significance of such findings, should they be established, has largely been implicit in our discussion thus far, but obviously the validation of such claims, or alternatively, the confirmation of all these rumors over the years, would have far-reaching and possibly baleful consequences for a conventional materialist view of science. By the same reasoning, empirical support for sight in the blind would be consistent with various "New Paradigm" visions of science that are rooted in nonlocal, nondual or holonomic perspectives in which consciousness is the primary reality. Furthermore, such findings would raise profound questions, from any scientific perspective, about $\mathrm{mind} /$ body relationships, the role of the brain in vision, and indeed the very mechanisms of sight.

Even within the more limited confines of parapsychological thought, such data would have a critical bearing on hypotheses having to do with the nature of OBEs and NDEs themselves. For example, V. Krishnan (1983) has argued that the perceptions reported during OBEs may have a physical basis. As a test of this hypothesis, Krishnan has proposed that the OBEs of congenitally blind persons should be distinct from those with sight. Irwin, in his discussion of this issue, framed the implications neatly:

Specifically, because people who surgically regain their sight take some time to learn visual identification of objects, the initial OBEs in the congenitally blind should exhibit the same property if the experience depends upon the visual pathways of the nervous system. The content of a congenitally blind subject's OBE therefore may speak to Krishnan's notion of the physical basis of out-of-body visual impressions. (Irwin, 1987, p. 54)

Our data will thus provide a crucial test of Krishnan's hypothesis, as well as speak to the long-standing controversy in parapsychology over whether the OBE represents some kind of true extrasomatic state or only a retrospective reconstruction based on sensory cues and imaginal processes. In any case, the possible epistemological and metaphysical implications of our findings potentially touch on deep conundrums and perennial concerns in the history of both normal and anti-establishment science.

Insofar as the specific and limited objectives of this study are concerned, however, there were three that formed the basis of this inquiry. Each can be phrased as a question. First, because we were chiefly interested in NDEs in this research, there is a necessary pre- 
liminary question we need to answer to which no previous systematic investigation has even been addressed: do blind persons in fact have NDEs and, if they do, are they the same as or different from those of sighted persons? Second, do blind persons, if they do report either NDEs or OBEs, claim to have visual perceptions during these experiences? And, finally, if such claims are made, is it ever possible to corroborate them through independent evidence or the testimony of other witnesses? In other words, can one establish that these claims are something other than mere fantasies or hallucinations?

These were the issues, then, this study was designed to probe.

\section{Method}

\section{Procedure}

In order to recruit qualified participants for this study, that is, blind persons who believed they had had either an NDE or an OBE, we first made contact with 11 national, regional, and state organizations for the blind, to solicit their help in locating potential respondents among their membership. Toward this end, we provided a notice to these organizations about our research that was then included in their respective publications, most of which were distributed in Braille or in the form of an audio cassette, providing our phone number and address and inviting interested individuals who believed they qualified to take part in this study to call or write us. A similar announcement was also published in Vital Signs, the newsletter of the International Association for Near-Death Studies. Finally, we alerted a few of our colleagues in the field of near-death studies about our project and asked them to refer any potentially eligible candidates to us.

After an individual made contact with us, we conducted a screening interview over the telephone to make sure that he or she had the appropriate qualifications for our study. Specifically, we determined the sight status of the person and made sure that he or she had undergone either an NDE or one or more OBEs, not necessarily associated with a near-death crisis. Once the person's eligibility for the study was established, we either then continued with the formal interview or scheduled a second call for that purpose. In a few cases, one or more follow-up calls were necessary to clarify some aspects of the respondent's account. In the interview, we took a detailed sight 
history from the individual and then conducted an in-depth probe about his or her relevant experiences. This portion of the interview was modeled on the format originally devised by Kenneth Ring (1980), but was tailored to the specific interests of this study and the special characteristics of our respondents. In the course of this interview, particular attention was given to obtaining information about events or perceptions that in principle could be corroborated by external witnesses or medical records. Where those witnesses could be specifically identified or relevant records secured, we made efforts to gain access to them and, when possible, to interview the witnesses about their own recollections of the events or perceptions described by the respondent.

All conversations were tape recorded with the permission of the respondent, and transcripts based on these conversations were later prepared, to permit detailed analysis of our findings. Finally, each participant who expressed an interest to receive information about the findings of this study was sent a summary at its conclusion.

\section{Subjects}

Of the 46 persons who were screened for this study, 31 qualified for inclusion and were interviewed. All but three of this final sample had heard about our study through the notices we had distributed. The exceptions were two persons referred to us by professional colleagues and one individual who came fortuitously to the attention of one of us as a result of meeting her husband while traveling to a professional conference.

Demographically, our sample consisted of 20 females and 11 males whose ages ranged from 22 to 70 years. They were all Caucasian, overwhelmingly Christian with respect to their original religious tradition, but varied greatly regarding their educational attainment and occupation.

Experiential Status. Sixteen of our respondents had survived an NDE, while an additional five persons had undergone both an NDE and one or more OBEs on other occasions not associated with their near-death incident. Thus, the total number of near-death experiencers (NDErs) in this sample was 21 . The remaining 10 were persons who had one or more OBEs only.

Of our NDErs, 13 had their experience in connection with an illness or a surgical procedure; six as a result of an accident, usually 
involving an automobile; two were mugged; one was nearly killed by being raped; one almost perished in combat; and one survived a suicide attempt. (The totals here are 24 experiences since three persons had two separate NDEs each and were therefore counted twice in these tabulations.)

Most of the OBEs reported occurred during states of bodily quiescence or relaxation, though some were occasioned by traumas, such as falls or rapes. The great majority of these episodes were not deliberately induced, though a few persons in our sample did try on occasion to bring them about through an act of will.

Sight Status. Not quite half of our total sample, 14, was comprised of persons blind from birth. A few of our respondents classified as blind from birth either had some limited light perception as children or have retained some as adults, but a distinct majority of persons in this category were without even any light perception at the time of their NDE or OBE. An additional 11 persons fell into the category of adventitiously blind, which means they lost their sight sometime after 5 years of age. The remaining six persons in our study were individuals who were severely visually impaired, most of them having at best only minimal non-delineated vision.

With respect to our two main experiential categories, NDEs and OBEs, the breakdown on sight status is as follows: among the 21 NDErs, 10 were blind from birth, nine adventitiously blind, and two severely visually impaired; among the remaining 10 out-of-body experiencers (OBErs), four were blind from birth, two adventitiously blind, and four severely visually impaired.

Of the 14 respondents blind from birth, two were congenitally blind and one had both his eyes removed by the time he was $4 \frac{1}{2}$ years old. The remaining 11 were born prematurely between 1946 and 1958 and all were placed in incubators where they received excessive concentrations of oxygen resulting in blindness. These individuals developed retrolental fibroplasia (RLF), now commonly referred to as retinopathy of prematurity (ROP).

Of our 11 adventitiously blind respondents, seven lost their vision between the ages of 16 and 41 as a result of illness or accident. In some cases, it was their near-death event itself that caused their blindness. The other four lost their vision between the ages of 13 and 52 due to slow degenerative eye diseases including retinitis pigmentosa (RP), glaucoma, and aging.

Three of our six visually impaired respondents developed RLF; two had RP, both of whom had limited peripheral vison (14 and 20 degree 
field, respectively); and one was born with cataracts and developed glaucoma as a teenager. All six have been legally blind from birth and only three of these individuals have been able to read any print at all.

\section{Results}

\section{NDEs in the Blind}

To examine the nature of NDEs in the blind, we must of course restrict ourselves to the 21 respondents in our sample, 12 women and nine men, who reported NDEs. Our findings with respect to this issue are unequivocal: blind persons, even those blind from birth, recount experiences that clearly conform to the familiar prototype of the beatific NDE first popularized in Moody's book, Life After Life (1975). Their narratives, in fact, tend to be indistinguishable from those of sighted persons with respect to the elements that serve to define the classic NDE pattern, such as the feelings of great peace and well-being that attend the experience, the sense of separation from the physical body, the experience of traveling through a tunnel or dark space, the encounter with the light, the life review, and so forth.

Before we turn to a statistical summary of our findings, however, it will be helpful to present a couple of illustrative cases in order to provide a sense of the actual narrative texture of these experiences. In doing so, we will unavoidably discover some unmistakable evidence pertaining to our second, but primary, question, having to do with whether the blind see during their NDEs. Nevertheless, we must defer a detailed consideration of this issue for the time being since our purpose here is chiefly to report what some of our respondents told us they remembered when they found themselves hovering between life and death. Because of space limitations, we will be able to present only one case in depth, but we will follow it up with a synopsis of a second comparable instance. Cases that we recount below with complete names are used with the respondent's permission; if only a first name is given to identify a case for purposes of reference, it is a pseudonym.

\section{Vicki Umipeg}

Vicki Umipeg is a married 43-year-old woman who has had two near-death experiences. The first, when she was 12 years old, oc- 
curred as a result of appendicitis and peritonitis. Her second NDE took place almost exactly a decade later, when she was seriously injured in an automobile accident.

Vicki was born very prematurely, having been in the womb only 22 weeks at delivery, and weighed just three pounds at birth. Afterward, her weight dropped precariously to one pound, 14 ounces. As was common for premature babies in the $1950 \mathrm{~s}$, she was placed in an airlock incubator through which oxygen was administered. Unfortunately, because of a failure to regulate the concentration of oxygen properly, Vicki was given too much and, along with about 50,000 other premature babies born in the United States about the same time, suffered such optic nerve damage as to leave her completely blind. As she made clear in an initial interview with another researcher, Greg Wilson, who kindly provided his tapes and transcripts to us, she has never had any visual experience whatever, nor does she even understand the nature of light:

Interviewer: Could you see anything?

Vicki: Nothing, never. No light, no shadows, no nothing, ever.

Interviewer: So the optic nerve was destroyed to both eyes?

Vicki: Yes, and so I've never been able to understand even the concept of light.

Interestingly, the overall form of Vicki's two experiences, which were separated by a period of 10 years, was extremely similar, almost as though they were replays of one another, albeit with some variations owing to the particularities of Vicki's life circumstances on each occasion. To minimize redundancy, we will present a fairly full exposition here only of Vicki's second NDE, since according to her own testimony, it was the more detailed and vivid of the two.

In early 1973 , Vicki, then 22 , was working as an occasional singer in a nightclub in Seattle. One night, at closing time, she was unable to call for a taxi to drive her home and circumstances forced her to take the only other option: a ride with a couple of inebriated patrons. Not surprisingly, a serious accident ensued during which Vicki was thrown out of their van. Her injuries were extensive and life-threatening, and included a skull fracture and concussion, and damage to her neck, back, and one leg. In fact, it took her a full year after being released from the hospital before she could stand upright without the risk of fainting.

Vicki clearly remembers the frightening prelude to the crash itself, but she has only a hazy recall of finding herself alternately out of 
her body and then back inside of it at the accident scene. Her only definite recollection of anything external to herself while out-of-body is a very brief glimpse of the crumpled vehicle. Although this aspect of her experience was confusing, she does claim that while in her out-of-body state she was aware of being in a nonphysical body that had a distinct form and that was, as she put it, "like it was made of light."

She has no memory of the her trip to Harborview Hospital in the ambulance, but after she arrived at the emergency room, she came again to awareness when she found herself up on the ceiling watching a male doctor and a woman-she is not sure whether the woman was another physician or a nurse-working on her body. She could overhear their conversation, too, which had to do with their fear that because of possible damage to Vicki's eardrum, she could become deaf as well as blind. Vicki tried desperately to communicate to them that she was fine, but naturally drew no response. She was also aware of seeing her body below her, which she recognized by certain identifying features, such as a distinctive wedding ring she was wearing.

According to her testimony, Vicki first had a very fleeting image of herself lying on the metal table and she was sure, she said, that "it was me," although it took her a moment to register that fact with certainty. As she later told us:

I knew it was me. ... I was pretty thin then. I was quite tall and thin at that point. And I recognized at first that it was a body, but I didn't even know that it was mine initially. Then I perceived that I was up on the ceiling, and I thought, "Well, that's kind of weird. What am I doing up here?" I thought, "Well, this must be me. Am I dead?. . . . I just briefly saw this body, and ... I knew that it was mine because I wasn't in mine. Then I was just away from it. It was that quick.

Almost immediately after that, as she recalls, she found herself going up through the ceilings of the hospital until she was above the roof of the building itself, during which time she had a brief panoramic view of her surroundings. She felt very exhilarated during this ascension and enjoyed tremendously the freedom of movement she was experiencing. She also began to hear sublimely beautiful and exquisitely harmonious music akin to the sound of wind chimes.

With scarcely a noticeable transition, she then discovered she had been sucked head-first into a tube and felt that she was being pulled up into it. The enclosure itself was dark, Vicki said, yet she was aware that she was moving toward light. As she reached the opening 
of the tube, the music that she had heard earlier seemed to be transformed into hymns, similar to those she heard during her previous NDE, and she then "rolled out" to find herself lying on grass.

She was surrounded by trees and flowers and a vast number of people. She was in a place of tremendous light, and the light, Vicki said, was something you could feel as well as see. What the light conveyed was love. Even the people she saw were bright and reflected the light of this love. "Everybody there was made of light. And I was made of light. There was love everywhere. It was like love came from the grass, love came from the birds, love came from the trees."

Vicki then became aware of five specific persons she knew in life who were welcoming her to this place. Debby and Diane were Vicki's blind schoolmates, who had died years before, at ages 11 and 6 , respectively. In life, they had both been profoundly retarded as well as blind, but here they appeared bright and beautiful, healthy and vitally alive, and no longer children, but, as Vicki phrased it, "in their prime." In addition, Vicki reports seeing two of her childhood caretakers, a couple named Mr. and Mrs. Zilk, both of whom had also previously died. Finally, there was Vicki's grandmother, who had essentially raised Vicki and who had died just two years before this incident. Her grandmother, who was further back than the others, was reaching out to hug Vicki. In these encounters, no actual words were exchanged, Vicki says, but only feelings of love and welcome.

In the midst of this rapture, Vicki was suddenly overcome with a sense of total knowledge:

I had a feeling like I knew everything . . . and like everything made sense. I just knew that this was where ... this place was where I would find the answers to all the questions about life, and about the planets, and about God, and about everything. . . . It's like the place was the knowing.

And then she was indeed flooded with information of a religious nature as well as scientific and mathematical knowledge. She came to understand languages she didn't know. All this overwhelmed and astonished her:

I don't know beans about math and science. . . . I all of a sudden understood intuitively almost things about calculus, and about the way planets were made. And I don't know anything about that. . . . I felt there was nothing I didn't know.

As these revelations were unfolding, Vicki noticed that now next to her was a figure whose radiance was far greater than the illumi- 
nation of any of the persons she had so far encountered. Immediately, she recognized this being to be Jesus, for she had seen him once before, during her previous NDE. He greeted her tenderly, while she conveyed her excitement to him about her newfound omniscience and her joy at being there and with him again.

Telepathically, he communicated to her: "Isn't it wonderful? Everything is beautiful here, and it fits together. And you'll find that. But you can't stay here now. It's not your time to be here yet and you have to go back."

Vicki reacted, understandably enough, with extreme disappointment and protested vehemently, "No, I want to stay with you." But the being reassured her that she would come back, but for now, she had to "go back and learn and teach more about loving and forgiving."

Still resistant, however, Vicki then learned that she also needed to go back to have her children. With that, Vicki, who was then childless but who "desperately wanted" to have children-and who has since given birth to three-became almost eager to return and finally consented.

However, before Vicki could leave, the being said to her, in these exact words, "But first, watch this."

And what Vicki then saw was "everything from my birth" in a complete panoramic review of her life, and as she watched, the being gently commented to help her understand the significance of her actions and their repercussions.

The last thing Vicki remembers, once the life review had been completed, are the words, "You have to leave now." She then experienced "a sickening thud" like a roller-coaster going backwards, and found herself back in her body, feeling heavy and full of pain.

\section{Brad Barrows}

A second case is that of Brad Barrows, a 33-year-old man living in Connecticut, who had a near-death experience in the winter of 1968 when he was only 8 years old. At the time, he was a student at the Boston Center for Blind Children, and had contracted a severe case of pneumonia and eventually had severe breathing difficulties. Afterward, he was told by nurses that his heart had stopped, apparently for at least four minutes, and that cardiopulmonary resuscitation (CPR) had been necessary to bring him back. 
Brad remembers that when he couldn't breathe any longer, he felt himself lifting up from the bed and floating through the room toward the ceiling. He saw his apparently lifeless body on the bed. He also saw his blind roommate get up from his bed and leave the room to get help. (His roommate later confirmed this.) Brad then found himself rapidly going upward through the ceilings of the building until he was above the roof. At this point, he found that he could see clearly.

He estimates that it was between $6: 30$ and 7:00 in the morning when this happened. He noticed that the sky was cloudy and dark. There had been a snowstorm the day before, and Brad could see snow everywhere except for the streets, which had been plowed, though they were still slushy. He was able to give us a very detailed description of the way the snow looked. Brad could also see the snowbanks that the plows had created. He saw a street car go by. Finally, he recognized a playground used by the children of his school and a particular hill he used to climb nearby.

When asked if he "knew" or "saw" these things, he said: "I clearly visualized them. I could suddenly notice them and see them. . . . I remember . . . being able to see quite clearly."

After this segment of this experience, which happened very fast, was over, he found himself in a tunnel and emerged from it to find himself in an immense field illuminated by a tremendous, all-encompassing light. Everything was perfect.

Brad could clearly see in this domain, too, though he commented that he was puzzled by the sensation of sight. He found himself walking on a path surrounded by tall grass, and also reported seeing tall trees with immense leaves. No shadows were visible, however.

While in this field, Brad became aware of beautiful music, like nothing he had ever heard on earth. Walking toward the sound, he came to and climbed a hill, eventually encountering a glittering stone structure so brilliant that he thought it might be burning hot. But it wasn't, and he entered it. The music continued here as well and, to Brad, seemed to be praising God. In this structure, Brad encountered a man whom he didn't recognize but from whom emanated an overwhelming love. The man, without a word, gently nudged Brad backward, initiating a reversal of his experience, ending with his finding himself in bed gasping for air, attended by two nurses. Brad, like Vicki, has been blind from birth. 
These two cases, which took place a continent apart and before the advent of modern near-death studies, show an obvious structural similarity and clearly exemplify the familiar Moody-type pattern of NDEs. To be sure, not all of the NDEs described by our blind respondents are as rich in their narrative line as those of Vicki and Brad, but there is no question that the great preponderance of these experiences conform to the classic form of the NDE.

To examine this point from a statistical perspective and help to provide something of an overview of our findings here, we can list a number of the common features of NDEs and state how often they are mentioned in the interviews of our 21 respondents in the NDEr category. Feelings of peace, well-being, or being loved were reported in 20 interviews; a sense of separation from the physical body, or an actual out-of-body experience (OBE), in 14; seeing one's own physical body, in 10; going through a tunnel or dark space, in eight; meeting others, such as spirits, angels, or religious personages, in 12; seeing a radiant light, in eight; hearing noise or music, in seven; a life review, in four; encountering a border or limit, in six; and a choice or being told to return to life, in 10 .

In general, although the numbers in the various sight categories (that is, blind from birth, adventitiously blind, and severely visually impaired) were too small to permit statistical tests, inspection reveals no obvious differences among sight subgroups with respect to the frequency of NDE elements. Thus, whether one is blind from birth, loses one's sight in later life, or suffers from severe visual impairment, the type of NDE reported appears to be much the same and is not structurally different from those described by sighted persons.

With these facts established, we can now turn our attention to our principal interest in this study, namely, whether and to what extent blind persons claim to be able to see during their NDEs and OBEs.

\section{Visual Aspects of NDEs and OBEs in the Blind}

We have already had evidence from the summaries of Vicki's and Brad's narratives that there appear to be clear visual representations, both of things of this world and of an otherworldly nature, during the NDEs of blind persons. The question we face here, however, is how common such testimony is among our respondents as a whole. 
First, let us look at how many of our respondents report being able to see during their NDEs or OBEs. Of our 21 NDErs, 15 claimed to have had some kind of sight, three were not sure whether they saw or not, and the remaining three did not appear to see at all. All but one of those who either denied or were unsure about being able to see came from those who were blind from birth, which means that only half of the NDErs in that category stated unequivocally that they had distinct visual impressions during their experience. Nevertheless, it is not clear by any means whether those respondents blind from birth who claimed not to have seen were in fact unable to, or simply failed to recognize what seeing was. For instance, one man whom we classified as a nonvisualizer told us that he could not explain how he had the perceptions he did because “I don't know what you mean by 'seeing.' " $\mathrm{He}$ was not the only such person to admit such perplexity, so that even among those cases we felt obliged to classify as not involving sight, the possibility is not entirely foreclosed. As a whole, however, our data here are quite consistent in indicating that the preponderance of our blind NDErs do indeed report vision during their near-death encounters, while only a minority are unsure about the matter or, in some cases, have no clear sense of sight.

Evidence of vision is even stronger among the OBErs in our sample. Nine of our 10 OBErs claimed sight, and if we include the five persons who had both an NDE and one or more OBEs on other occasions, the figures are 13 out of 15 . In this connection, one of the NDErs whom we classified as a nonvisualizer during her NDE did report vision during her OBEs.

Overall, the number of persons who indicated they had some kind of vision, either during an NDE or OBE, was 25, which was 80 percent of our entire sample. Even for those blind from birth, 9 of 14, or 64 percent, likewise reported sight.

Given that some kind of vision is the rule for the blind, we can go on to ask, just what do they see?

In general, they report the same kinds of visual impressions as sighted persons do in describing NDEs and OBEs. For example, 10 of our 21 NDErs said they had some kind of vision of their physical body, and seven of our 10 OBErs said likewise. Occasionally, there are other this-worldly perceptions as well, such as seeing a medical team at work on one's body or various features of the room or surroundings where one's physical body was. Otherworldly perceptions abound, too, and for NDErs, as we have already seen, they seem to 
take the form characteristic for transcendental NDEs of sighted persons: radiant light, otherworldly landscapes, angels or religious figures, deceased relatives, and so forth. Somewhat similar otherworldly perceptions are sometimes found for OBErs as well, though these, when they occur, are usually limited to seeing light, beautiful colors, and meeting others. None of our OBErs recounted a life review.

How well do our respondents find they can see during these episodes? We have already noted that the visual perceptions of Vicki and Brad appeared extremely clear and detailed, especially when they found themselves in the otherworldly portions of their neardeath journeys. While not all of our blind NDErs had clear, articulated visual impressions, nevertheless enough of them did so that we can conclude that the NDE cases like Vicki's and Brad's are fairly typical in this regard. For instance, one of our interviewees whose sight perished completely as a result of a stroke at age 22 , and was near-sighted before that, told us in connection with seeing her body, her doctor, and the operating room during her NDE: "I know I could see and I was supposed to be blind. . . . And I know I could see everything. . . . It was very clear when I was out. I could see details and everything."

Another man, who lost his vision in a car accident at the age of 19 , had a comforting vision of his deceased grandmother across a valley during his NDE. In commenting on his clarity, he said: "Of course I had no sight because I had total destruction of my eyes in the accident, but [my vision] was very clear and distinct. . . . I had perfect vision in that experience."

Still another man, this one blind from birth, found himself in an enormous library during the transcendental phase of his NDE and saw "thousands and millions and billions of books, as far as you could see." Asked if he saw them visually he said, "Oh, yes!" Did he see them clearly? "No problem." Was he surprised at being able to see thus? "Not in the least. I said, 'Hey, you can't see,' and I said, 'Well, of course I can see. Look at those books. That's ample proof that I can see.'"

Typically, vision is reported as clear, even acutely so, by our respondents in the otherworldly domain, where seeing is often described as "perfectly natural" or "the way it's supposed to be." However, sometimes the initial onset of visual perception of the physical world is disorienting and even disturbing to the blind. This was true for Vicki, for example, who said: 
I had a hard time relating to it [i.e., seeing]. I had a real difficult time relating to it because I've never experienced it. And it was something very foreign to me. . . . Let's see, how can I put it into words? It was like hearing words and not being able to understand them, but knowing that they were words. And before you'd never heard anything. But it was something new, something you'd not been able to previously attach any meaning to

Later, in commenting on the shock of these initial visual impressions, she even used the word "frightening" to characterize them. She also told us that she was never able to discriminate colors as such, but only "different shades of brightness," about which impressions she could only wonder afterward whether they represented what sighted people meant by color.

However, after this brief and confusing period of adjustment, the experiencer's perception quickly seems to become self-organizing and coherent; then it is as if the individual has been seeing his or her whole life. As Brad commented on the naturalness of his own perception in the otherworldly domain:

It was like it was always there. . . It was so natural it was almost as if I should have always been able to see like that. . . . I could never understand why I never could do that back in my own body, yet it was so unbelievably natural. ... I thought to myself I should be able to carry this right back with me. It's just something I've always had. . . I I was very comfortable with it.

To conclude this section, we would like to bring all of these visual threads together in one specific illustrative case of still another of our blind respondents, a woman we'll call Marsha. Marsha is a 40year-old married woman living in Connecticut who had an NDE on January 16,1986 , when she was 32 , as a result of complications in her pregnancy.

Like Vicki, Marsha was a premature baby, having been born after only a six month pregnancy, and, as a result, had developed a condition of retinopathy of prematurity. Unlike Vicki, however, she has always had some limited vision. In this respect, Marsha told us: "I have some vision in my left eye, not a whole lot. I don't have any reading vision-I can't read print at all, but I can see, like, people and stuff, but they look . . . blurry." We classified Marsha in the severely visually impaired category, as her actual vision was extremely poor and she uses a guide dog.

Marsha's case is mainly of interest here in showing how the visual perception of a severely visually impaired individual during an NDE 
is not only enhanced, but can become virtually perfect. In her interview with us, she made it plain that her heightened acuity pertained both to her out-of-body perception as well as to that which she experienced in the otherworldly portion of her experience. As to the former, Marsha told us that when she was coming back, she was aware of seeing her body:

Interviewer: Could you describe it? Could you see it in detail?

Marsha: Yeah, it just looked like me. I was, like, asleep.

Interviewer: And how was your vision, if I could put it that way, when you were looking down on yourself?

Marsha: It was fine. . . It was normal.

Interviewer: When you say normal, you mean clear?

Marsha: Yeah, everything. There was no problem with it.

Concerning the quality of her otherworldly perception, she commented:

Interviewer: Were you able to see better than you could in the physical world?

Marsha: Oh, yeah.

Interviewer: What was your visual perception like in this room [in the otherworldly portion of her NDE]?

Marsha: Everything, I could see everything. . . . All the people, all the way back. Everything.

Interviewer: In what way? Could you be a little more specific?

Marsha: It was perfect. It would not be like that here. There was no problem. It was, like, you know- everything, you could see everything. It was not like your eyes. I don't know what normal vision would feel like. It was not like your eyes see. It couldn't be my eyes because my eyes were back over here. I could see gold in the room. Gold on the walls. There [were] white birds and angels and all these people.

Interviewer: When you saw birds and the people and the room, were you seeing it in detail or just like you see now?

Marsha: No, no. It was detail. It was white light. Everything was white light in there. And there was gold on the walls.

Later on, in elaborating on her perception of colors during this part of her experience, Marsha was similarly definite about what she was aware of:

Interviewer: And could you see it [color] clearly in the experience?

Marsha: Yes. Everything was the way it was supposed to be.

Finally, when the interviewer probed to get Marsha's further thoughts on her visual experience during her NDE, this exchange occurred: 
Interviewer: If you had to say how much sight you actually had at the time of your experience, is there a way for you to describe it? Marsha: It was, like, perfect. I don't see how it could not be perfect. I can't say I could see like I see now. . . . I could see everything [then].

Interviewer: Do you have any thoughts on the fact that you had vision during this experience?

Marsha: Well, see, it was vision, but I don't think it was my eyes. I don't know how it works because my eyes were back here, and since they are not right and I could see everything right, there had to be more special vision somehow.

Although Marsha still has some residual physical vision, it is clear that her comments echo both those of Vicki and Brad concerning the quality of her visual perception, especially in the otherworldly realm. There, she saw perfectly and in detail that was astonishing to her and for which she had no explanation. And like Vicki and Brad, who had also noted the naturalness of their otherworldly vision, Marsha used a phrase we have encountered before, namely, "everything was the way it was supposed to be." Likewise, her visual impression of her physical body seemed clear and distinct, in contrast to her everyday vision. Overall, her testimony was as striking as it was consistent and showed that severely visually impaired persons, too, may find that coming close to death appears to restore their sight to normal, and perhaps even superior, acuity.

In summary, as a whole our interviews with both NDErs and OBErs offered abundant testimony that reports of visual perception among the blind are common, that their impressions concern both things of this world and otherworldly domains, and that they are often clear and detailed, even in narratives furnished by those who have been blind from birth.

\section{Corroborative Evidence for OBE and NDE Visions}

Obviously, in order to demonstrate that the perceptions described by our blind experiencers are something other than mere fantasies or even complex hallucinations, it will be necessary to provide some kind of confirming evidence for them, preferably from other independent witnesses or from reliable documentation. But just here, not surprisingly, is where it proves difficult to gather the type of indispensable corroboration that would help to cinch the argument that 
what they report seeing is indeed authentic. In many cases, such as those of Vicki and Brad, the reported NDEs or OBEs took place so long ago that it is no longer possible to know precisely who the witnesses were or where to locate them. In other instances, potential informants have died or were not accessible to us for interviews. As a result, much of the testimony of our respondents is dependent on their own truthfulness and the reliability of their memories. As a rule, we did not have cause to question the sincerity of our respondents, but sincerity is not evidence and one's own word is hardly the last word when it comes to evaluating the validity of these accounts.

Nevertheless, in at least some instances, we are able to offer some evidence, and in one case some very strong evidence, that these claims are in fact rooted in a direct and accurate, if baffling, perception of the situation. In this section, we will present two of our cases in which we could document some measure of evidentiality for the visual perceptions of the blind.

\section{Frank}

Our first example is one of apparently veridical perception during an $O B E$ in which a respondent claimed to have seen himself. What makes this case of special interest, however, is that he also saw something he couldn't have known about by normal means. Furthermore, he told us that a friend of his was in a position to confirm his testimony. Frank is 66 years old, but lost his sight completely in 1982. He cannot see anything now, including light or shadows. He has had several OBEs, however, since becoming totally blind. What follows is his recall of one of them.

Around 1992, a friend of Frank's was going to be driving him to the wake of a mutual friend. As Frank remembered the incident:

And so I said to her that morning, I said: "Gee, I haven't got a good tie to wear. Why don't you pick me up one?" She said, "Yeah, I'll pick you up one when I get down to Mel's [a clothing store]." So she picked it up and dropped it off and said, "I can't stay. I've got to get home and get ready to pick you up to go to the wake." So I got dressed and put the tie on. She didn't tell me the color of the tie or anything else. I was laying down on the couch and I could see myself coming out of my body. And I could see my tie. The tie that was on. And it had a circle on it-it was a red-and it had a gray circle, two gray circles on it. And I remember that. 
The interviewer then probes for further details and clarification:

Interviewer: Now just for the chronology of it, you were lying down with this tie on, you saw yourself going out of the body, and then you saw the tie?

Frank: I saw the tie 'cause I told her the color.

Interviewer: You told your friend who was driving you?

Frank: Yeah, when she came back to pick me up. . . And when she came down to pick me up, I said to her, "Are the circles gray in this tie?" And she says, "Yes."

Interviewer: Was she surprised that you knew?

Frank: Yes. She said, "How did you know?" She said, "Did anyone come here?" I said, "No, nobody came here." You know, you can't tell 'em [laughs], 'cause they just don't accept, they don't believe in it.

Interviewer: And do you remember what the tie looked like even now?

Frank: Yeah. It's a rose-colored tie with circles on it and dots in the middle of the circle. Whitish/grayish circle around there. And it's a beautiful tie, 'cause every place I go they remark on it. So she said to me, "Who told you?" And I said, "Nobody." I said, "I just guessed." I didn't want to tell because, like I said before . . y you can't say things to certain people.

Naturally, after hearing this story, we were eager to see if we could track down the woman involved in this incident. That proved difficult, since Frank had lost contact with her, but eventually he was able to locate her and, without telling her exactly why we were interested to talk with her, put us in touch with her. One of us (S.C.) did conduct an open-ended interview with this woman shortly afterward and summarized it as follows in her notes:

I independently called his friend who said she did purchase a tie for Frank that day and did pick him up for the wake. However, she didn't have a clear recollection of the sequence of events that day to confirm the accuracy of Frank's story and didn't remember the exact design and colors of the tie. She added that Frank is a downto-earth guy who in her experience does not embellish stories. And even though she couldn't independently corroborate his account, she tended to think he was probably accurate in recounting the details.

So here, although we lack the crucial confirming facts we need from the witness involved, we nevertheless have a highly suggestive instance that this man's recall of his experience is essentially accurate. However, the obvious weaknesses in and ultimate inconclusiveness of this case were overcome in our second example, in which a 
direct and independent corroboration of the respondent's own testimony was obtained.

\section{Nancy}

The next respondent was a 41-year-old woman we will call Nancy who underwent a biopsy in 1991 in connection with a possible cancerous chest tumor. During the procedure, the surgeon inadvertently cut her superior vena cava, then compounded his error by sewing it closed, causing a variety of medical catastrophes including blindness, a condition that was discovered only shortly after surgery when Nancy was examined in the recovery room. She remembers waking up at that time and screaming, "I'm blind, I'm blind!"

Shortly afterward, she was rushed on a gurney down the corridor in order to have an angiogram. However, the attendants, in their haste, slammed her gurney into a closed elevator door, at which point the woman had an out-of-body experience.

Nancy told us she floated above the gurney and could see her body below. However, she also said she could see down the hall where two men, the father of her son and her current lover, were both standing, looking shocked. She remembers being puzzled by the fact that they simply stood there agape and made no movement to approach her. Her memory of the scene stopped at that point.

In trying to corroborate her claims, we interviewed the two men. The father of her son could not recall the precise details of that particular incident, though his general account corroborated Nancy's, but her lover, Leon, did recall it and independently confirmed all the essential facts of this event. Here is an excerpt from our interview with him, which bears on this crucial episode.

Leon: I was in the hallway by the surgery and she was coming out and I could tell it was her. They were kind of rushing her out. Interviewer: Rushing her out of where?

Leon: Of the surgery suite where she had been in the recovery area, I think. And I saw these people coming out. I saw people wheeling a gurney. I saw about four or five people with her, and I looked and I said, "God, it looks like Nancy," but her face and her upper torso were really swollen about twice the size it should have been. At that point I looked and I said, "Nancy, Nancy," and they just-she didn't know, I mean. She was out of it. And they told me they were taking her down for an angiogram.

Interviewer: Who told you that? 
Leon: I believe a nurse did. I'm not quite sure. I think I was still in a state of shock. I mean, it had been a long day for me. You're expecting an hour procedure and here it is, approximately 10 hours later and you don't have very many answers. I believe a nurse did. I know I asked. And I think Dick [the father of Nancy's child] was there at the same time. I think he and I were talking in the hallway. Interviewer: Do you know how far you were from Nancy?

Leon: When I first saw her she was probably, maybe about 100 feet and then she went right by us. I was probably no more than 3 to 5 feet away from her. And I believe Dick was right next to me as well.

Interviewer: And do you know how they took her out? She was on the gurney?

Leon: She was on the gurney. There were IVs. . . . I'm not sure-I think she had some sort of a breathing apparatus. I'm not sure if it was an Ambu bag or what it was.

Interviewer: And then where did they take her?

Leon: They took her downstairs to do an angiogram.

Interviewer: How?

Leon: They took her down in the gurney in the service elevator. They didn't take her in a regular elevator. They took her around the corner to the service elevator.

Interviewer: And did you see that whole process?

Leon: Yes, I did.

Interviewer: Did you see her go into the elevator?

Leon: Yes, I did because I walked around to watch her enter the elevator.

Interviewer: Was there any disturbance that you remember in getting her into the elevator?

Leon: I think there was a real sense of urgency on the staff. I've worked in hospital emergency rooms as well and I can really relate to that. I think somebody was, like, trying to get into the elevator at the same time and there was some sort of a "Oh, I can't get in, let's move this over a little bit," kind of adjusting before they could get her into the elevator. But it was very swift.

Interviewer: Did you have a good look at her face?

Leon: Yeah, it really kind of shocked me. She was just really swollen. She was totally unrecognizable. I mean, I knew it was her but-you know, I was a medic in Vietnam and it was just like seeing a body after a day after they get bloated. It was the same kind of look.

Leon's account accorded with Nancy's in virtually every significant respect, despite the fact that he was very worried about her condition, and could scarcely recognize her because of her edema when he did see her. Yet, despite his evident state of shock at the time, his interview appeared to corroborate her story, as much as any external witness could be expected to. It should be noted that this witness has been separated from our participant for several years and 
they had not even communicated for at least a year before we interviewed him. Furthermore, even if Nancy had not been totally blind at the time, the respirator on her face during this accident would have partially occluded her visual field and certainly would have prevented the kind of lateral vision necessary for her to view these men down the hall. But the fact is, according to indications in her medical records and other evidence we have garnered, she appeared already to have been completely blind when this event occurred.

After a detailed investigation of this case and a review of all pertinent documentation, we have concluded that in all probability there was no possibility for Nancy to see what she did with her physical eyes which, in any event, were almost surely sightless at that time. Yet the evidence suggests that she did see, and, as the corroborative testimony we have quoted shows, she apparently saw truly.

The question, of course, is how she was able to do that, and not only how Nancy saw, but how any of the blind persons in our study saw what they certainly could not possibly have seen physically. Our findings in this section only establish a putative case that these visions are factually accurate, and not just some kind of fabrication, reconstruction, lucky guess, or fantasy; but they leave unexplained the paradox of our discovery that the rumors some of us have been hearing all these years, that the blind can actually see during their NDEs, appear to be true. Whether and how this can be so is the mystery we must next be prepared to probe.

\section{Discussion}

\section{An Overview of Our Findings}

Before tackling the perplexing and difficult questions we have just posed, it will be helpful to summarize our principal findings. To do so, we will return to the three issues this study was designed to address. The first of these was whether blind persons do report NDEs and, if they do, whether those NDEs are the same or different from those of sighted persons. Our findings here were unequivocal in the affirmative. There is no question that NDEs in the blind do occur and, furthermore, that they take the same general form and are comprised of the very same elements that define the NDEs of sighted individuals. Moreover, this generalization appears to hold across all three categories of blindness that were represented in this study: 
those blind from birth, those adventitiously blind, and those severely visually impaired.

The second issue, and the one that was the driving force of this study, was whether the blind claim to have visual impressions during their NDEs or OBEs. On this point, too, our data were conclusive. Overall, 80 percent of our respondents reported these claims, most of them in the language of unhesitating declaration, even when they had been surprised, or even stunned, by the unexpected discovery that they could in fact see. Like sighted experiencers, our blind respondents described to us both perceptions of this world and otherworldly scenes, often in fulsome, fine-grained detail, and sometimes with a sense of extremely sharp, even subjectively perfect, acuity.

The last issue hinged on the second, and that had to do with attempting to corroborate these claims of sight in an effort to show that they represented something other than fantasies or hallucinations. This was the weakest part of our study since, for a variety of methodological reasons, it was often not possible to locate relevant witnesses or gain access to potentially helpful documentation. Nevertheless, we did offer two illustrative and highly suggestive cases that seemed to indicate these claims are indeed authentic and not explicable by conventional means.

\section{Some Possible Explanations for Apparent Sight in the Blind}

With this summary of our findings we are now ready to explore the questions of central interest to us. The simplest way to frame the issue might be to ask: "How is it that the blind can see during these experiences?" But, however natural it might be to put the question in this form, doing so implies that we have already concluded that we can reasonably infer from our data that the blind do in fact see. That is certainly possible, perhaps even plausible, but not all readers would be prepared to concede the point. Indeed, we have already implied that from an epistemological point of view, it might be better to rephrase our basic question as: "If it can legitimately be said that the blind in some sense do see, in precisely what sense would that be?" Putting the question in this way, then, leaves open the issue of the nature of apparent sight in the blind. However, even before we can properly address this question, there is plainly still another one that must exert a prior claim on our attention, and that is: "Might there be some non-retinal-based mechanisms that could 
in principle account for the results of this study and thus demonstrate that vision in the blind is indeed only apparent and not actual?"

Thus, by a series of interrogative declensions, we find ourselves facing first the possibility of various alternative explanations that would avoid having to posit some kind of eyeless vision to subsume our findings. Before resorting to possible unconventional theories such as those rooted in New Paradigm science or even esoteric thought to interpret our findings, we must first make sure that no already recognized natural or prosaic mechanism cannot provide a superior or more parsimonious explanation.

\section{The Dream Hypothesis}

One fairly obvious possibility that has often been advanced in connection with the NDEs and OBEs of sighted persons is that this experience is some kind of a dream, perhaps a lucid or exceptionally vivid dream, which has such realistic properties that it is easily misinterpreted and thus given an ontological status it does not deserve. $\mathrm{Tb}$ evaluate this hypothesis, we first need to inquire into what is known about normal oneiric processes in the blind. Fortunately, there has been a great deal of research devoted to the dreams of the blind, some of it going back more than a hundred years. As a result of these investigations, certain generalizations about the presence of visual imagery in dreams appear to stand up quite well. Among these "empirical cornerstones" (Kirtley, 1975) are that (1) there are no visual images in the dreams of the congenitally blind; (2) individuals blinded before the age of 5 also tend not to have visual imagery; (3) those who become sightless between the age of 5 to 7 may or may not retain visual imagery; and (4) most persons who lose their sight after age 7 do retain visual imagery, although its clarity tends to fade with time. In addition, various researchers have found that audition tends to be the primary sense involved in dreams of the blind, with tactile and kinesthetic elements next (Kirtley, 1975).

In our interviews, we routinely asked our respondents about the nature of their dreams, and what we found in our sample accords with the generalizations just described. In addition, however, and particularly pertinent to the hypothesis under consideration, our respondents usually went on to say that not only were their NDEs unlike their usual dreams, but in the case of those blind from birth, 
they stood out as radically different precisely because they contained visual imagery, whereas their dreams had always lacked this element. Vicki, one of our NDErs blind from birth, provides a good case in point:

Interviewer: How would you compare your dreams to your NDEs?

Vicki: No similarity, no similarity at all.

Interviewer: Do you have any kind of visual perception in your dreams?

Vicki: Nothing. No color, no sight of any sort, no shadows, no light, no nothing.

Interviewer: What kinds of perceptions are you aware of in your typical dreams?

Vicki: Taste-I have a lot of eating dreams [laughs]. And I have dreams when I'm playing the piano and singing, which I do for a living, anyway. I have dreams in which I touch things. . . . I taste things, touch things, hear things, and smell things-that's it.

Interviewer: And no visual perceptions?

Vicki: No.

Interviewer: So that what you experienced during your NDE was quite different from your dreams?

Vicki: Yeah, because there's no visual impression at all in any dream that I have.

These remarks, along with similar asseverations from other participants in our study, make it abundantly clear that from our respondents' point of view, the NDE, especially its visual aspect, has nothing in common with their usual dreams. It is instead something in a class by itself and not to be conflated with dreams. Since there is no support whatever from our interviews for the dream hypothesis of NDEs, we may confidently reject it as a potential explanation for our findings.

\section{Retrospective Reconstruction}

Another possibility, at least for the kind of visual perceptions respondents report during the out-of-body phase of NDEs, is that individuals are not really seeing at that time, but talking afterward as if they did. Instead, according to this hypothesis, they have actually reconstructed a plausible account after the fact of what might be expected to have happened while they were close to death, although they may sincerely but erroneously believe that they witnessed it at the time. From a combination of prior expectations, familiarity with hospital routines, overheard conversations or other 
sensory cues at the time, information gleaned afterward, or even simply by lucky guesses, it might be possible for an NDEr to construct imaginatively a pictorial representation of events during an NDE. Thus, this hypothesis would contend that what appears to be vision is in reality a product of the mind's inventiveness.

The chief proponent of this hypothesis is Susan Blackmore (1993), who used it chiefly to discount some of the pioneering work by Michael Sabom (1982), in his study of apparently veridical, though seemingly impossible, visual perception in a sample of NDErs. In discussing, for example, how a patient could unconsciously use auditory information available during an operation, Blackmore indicated how naturally such a false representation could be generated:

It does not take much information from such sounds for a person to piece together a very convincing and realistic visual impression of what is going on. This will provide the best model they have and seem perfectly real. They may have no idea that the model was constructed primarily from things that they have heard. . . . It is very hard to assess just how much information any patient would have available. We can only remember the general point that people who appear unconscious may still be aware of some of the things going on around them and they can easily build these up into a good visual picture of what was happening (1993, pp. 124-125).

Blackmore's reasoning is logical and her hypothesis has a certain plausibility, but we have not been able to find any significant support for it among our interviewees. In fact only one of our 31 respondents even alluded to it, and at that merely as one theoretical possibility among several. Furthermore, a review of our transcripts affords no basis for arguing that retrospective reconstruction was likely to have played a role in most or even some of our cases. This same conclusion was reached by Sabom and independently by Scott Rogo (1989), in an evaluation of the former's work in regard to the possible relevance of this hypothesis.

And there are additional reasons for finding it inadequate here. For one, when one considers that it is an after-the-fact hypothesis that virtually cannot be disproved, the almost complete lack of direct evidence from our study in its behalf is particularly telling. Second, this hypothesis clearly founders when it comes to accounting for instances where unusual objects, ones that could not easily have been predicted or otherwise anticipated, such as the design and color of Frank's tie, are described by the blind. Third, it is completely impotent when it comes to accounting for the otherworldly segments of 
NDEs, which is especially clear in visual form for many of our respondents.

On the basis of these considerations, we find scant evidence in favor of this hypothesis, and a number of cogent reasons not only to reject it, but to be tempted to regard it almost as a kind of all-purpose refuge for the skeptically-minded, rather like the "super-ESP" hypothesis in parapsychology, which, in principle, is always capable of explaining away in a pseudoscientific fashion findings that threaten to disturb prevailing ideas of the possible.

\section{Blindsight}

In the early 1970 s, Lawrence Weiskrantz began to study a curious phenomenon he was later to call "blindsight" (Weiskrantz, 1986), in which patients suffering from extensive cortical blindness appeared to be able to "see." In his experiments, for example, Weiskrantz was able to show that in the absence of any visual sensation, patients, if asked to reach for a nearby object about whose exact location they were ignorant, tended to move in the right direction. Furthermore, when asked to grasp objects the nature of which was not disclosed to them beforehand, their hands tended spontaneously to assume the appropriate form necessary to hold the object. Weiskrantz's work has since been replicated by others (Humphrey, 1993) and the phenomenon has even been found in monkeys after extirpation of the visual cortex.

Is it possible, then, that what our respondents report is actually a form of blindsight?

Further scrutiny of the results of research into blindsight shows very quickly that although it seems to be a legitimate form of perception, it can by no means account for our findings. First of all, patients manifesting the effect typically cannot verbally describe the object they are alleged to see, unlike our respondents who, as we have noted, were usually certain about what they saw and could describe it often without hesitation. In fact, a cortically blind patient, even when his or her object identification exceeds chance levels, believes that it is largely the result of pure guesswork. Such uncertainties were not characteristic of our respondents. Second, even when performance is better than chance would allow, even the best of these patients still make many errors (Humphrey, 1993). While we cannot of course provide an overall figure of accuracy of object 
identification in our study, it is not obvious from our findings that errors were made in regard to reports of visual perception in those portions of the environmental visual field where attention was focused. Finally, and perhaps most crucially of all, blindsight patients, unlike our respondents, do not claim that they can "see" in any sense. As Humphrey wrote: "Certainly the patient says he does not have visual sensation. . . . Rather he says, 'I don't know anything at allbut if you tell me I'm getting it right $I$ have to take your word for it" " (1993, p. 90). This kind of statement is simply not found in the testimony of our respondents who, on the contrary, are often convinced that they have somehow seen what they report.

Thus, the blindsight phenomenon, however fascinating it may be in its own right, cannot explain our findings. Indeed, the term itself seems to be a bit of an unintentional misnomer, since in such patients there does not seem to be any conscious sense of visual perception at all.

\section{Skin-Based Vision}

The idea that we may have a kind of eyeless visual back-up system based on dermal sensitivity is an old one, although at first blush the notion may seem preposterous. Yet the retina itself is just a specialized piece of skin, which through evolution has come to be the "vision specialist" for the body. Therefore, it is certainly conceivable that in our skin itself there might be a residual basis for visual detection, which has simply atrophied and become nonfunctional through disuse, like a vestigial organ.

In fact, when one begins to explore the empirical basis for this hypothesis, one finds considerable evidence for it. The earliest work along these lines seems to have been done three-quarters of a century ago by Jules Romains. In 1920, he published a now nearly forgotten book called La Vision Extra-Rétinienne et la Sens Paroptique, which described his experiments in skin-based perception and became available in 1924 in an American translation under the title of Eyeless Sight: A Study of Extra-Retinal Vision and the Paroptic Sense. Romains' general purpose was to determine if individuals could "see" without the use of their eyes. To investigate this possibility, he first blindfolded his subjects in such a way as to ensure that no light could penetrate their eyes. He then ran them through a series of experiments to assess their visual capabilities under these conditions. 
In some, he would present them with a newspaper and ask them to read the headlines. In others, he would ask his subjects to "read" a set of numbers. In still others, as in modern blindsight experiments, he would invite them to describe an object he placed in front of or behind them, or ask his subjects to identify the colors of objects or to distinguish the colors of papers under glass.

In general, and quite astonishingly, Romains reported that his subjects performed remarkably well, far exceeding what would have been possible by chance. Furthermore, these experiments were witnessed by many observers, some of them quite eminent, and therefore do not depend solely on his own word. Romains found, however, that several conditions affected the probability of correct identification. First, even though the subjects were blindfolded, light had to be present in the room for them to be able to "see." Second, his subjects could not perceive the object or "read" the number or letters on a paper when an opaque screen or door was placed between them and the object. Finally, the greater the area of the skin actually exposed, the more accurate subjects tended to be in their descriptions.

Romains developed some elaborate theories to explain his findings, but however intriguing his discoveries were, for several distinct reasons they do not seem to have much bearing on what we found in our study. To begin with, in Romains' experiments, shielding the object from view prevented it from being "seen." Yet, in our study, even the presence of walls or ceilings proved to be no impediment to our respondents' apparent vision, as cases such as Vicki's and Brad's, among others, attest. In addition, whereas Romains found that the degree of skin exposure was directly related to accuracy of perception, there was no evidence of that in our study, and in fact some evidence that would contravene it. Remember, for instance, that in some of our cases the respondent's body was covered with bedsheets or was clothed at the time of an NDE or OBE, yet vision seemed to occur without difficulty. Most telling of all, however, is that Romains' subjects generally took a long time to achieve whatever degree of visual accuracy they did demonstrate. Indeed throughout his book, Romains frequently commented that the kind of eyeless vision he obtained from his subjects was piecemeal, gradual, with the elements of perception coming together slowly, as a result of laborious effort, at least at the beginning. Eyeless vision, he wrote, is successive, a matter of trial-and-error, and tends at first to discern only objects near at hand. In our study, visual perception seemed to be immediate, unlearned, and was not restricted to objects close to the individual. Therefore 
we conclude, as we did with the later experiments in blindsight, that Romains' findings, even if valid, have no relevance for ours and must depend on entirely different mechanisms.

Incidentally, the insight underlying Romains' work, that there may be non-retinal mechanisms that afford a kind of vision, has been followed up by a succession of modern researchers (Bach-y-Rita, 1972; Duplessis, 1975; Grinberg-Zylberbaum, 1983), but their findings, although generally consistent with Romains', fail to explain ours. In general, this more modern research parallels Romains' observation that it takes a considerable amount of time and training for subjects to show even a modest proficiency of object recognition. That fact alone disqualifies the hypothesis of skin-based vision as a possible explanatory vehicle for our results.

The rejection of this hypothesis also implies that similar views, such as V. Krishnan's (1983), which contend that the vision reported in NDEs and OBEs may be a function of some kind of obscure physical mechanism are without support. For instance, Krishnan's position requires that congenitally blind persons, on seeing for the first time, have inchoate perception, as do those whose sight is restored through an operation (Gregory, 1966; Sacks, 1993; Valvo, 1970; von Senden, 1960). But, clearly, that is not the case. The brief surprise or disorientation a blind NDEr may experience when confronted with visual impressions before adjusting to them does not begin to compare with the hours of training that a newly sighted individual needs to undergo in order to transform visual information into meaningful patterns. Relatively speaking, then, sight is virtually immediate in our blind NDErs, and although there may be some confusion over the fact of sight and uncertainty about color, object perception seems stable from the outset. Moreover, when never-before-seeing NDErs find themselves in the transcendental portions of their experience, some of them remark that seeing was perfectly natural in that state; it was if they could always see. Any mechanism that could explain that baffling fact is, to us, truly obscure. In any event, the hypothesis that it might be rooted in some kind of skin-based vision, as Krishnan has also suggested, is without a shred of evidence.

\section{An Assessment of the Evidence for Alternative Explanations}

Our search for a non-retinal-based mechanism that could in principle account for the results of this study and thus demonstrate that 
vision in the blind is indeed only apparent and not actual has considered theories and data relating to dreams, retrospective reconstruction, blindsight, and skin-based vision, and has come up empty. Of course, it would be absurd to claim that we have exhausted the list of naturalistic or conventional possibilities or eliminated all conceivable artifacts, but we believe we have ruled out some of the most obvious candidates for explanatory honors. At the very least, we have perhaps managed to cast some doubt on the tenability of this type of explanation for our findings, and consequently increased the likelihood that however they might be accounted for, we would do best to seek elsewhere for our answers.

In any case, having addressed this basic issue, we can now revert to the question we posed earlier about whether or in what sense it can be said that the blind do see. Clearly, before any explanation for vision in the blind can be accepted, it must first be established that their reports reflect the operation of something that can legitimately be called "true sight." That assumption has of course been implicit throughout this article and may perhaps appear to some to be selfevident by now. But it is not, and our next task is to demonstrate just why it is not.

\section{Apparent Vision in the Blind: Is It Really Seeing?}

We as researchers can never have access to the NDE or OBE in itself. Rather, every such experience is coded in a certain way as it occurs and afterward, and comes to us only later as a report in a linguistic form. Therefore, by the time we interview our respondents, the original experience has already been processed through several distinct filters and necessarily undergone a series of virtually unconscious transformations until it reaches us as a distinct and coherent narrative. Therefore, it will prove helpful to discern how this narrative comes to be shaped, and how the experience may be coded in the first place. Doing so will in turn shed light on the pivotal question of this section, namely: is what we discovered in our blind respondents truly a form of seeing? That is, is it in any sense something that might be conceived of as analogous to physical sight?

To answer these questions, we reviewed our transcripts as sedulously as possible for insights into the formative processes that ultimately gave rise to the verbal report of the NDE or OBE. And what we discovered in a finer reading of these documents were a brace of 
factors that together sounded a tocsin against an overly literal interpretation of these reports as indicative of "seeing" as such. For one thing, our scrutiny of these transcripts frequently revealed a multifaceted synesthetic aspect to the experiencer's perception that seemed to transcend simple sight. A number of our interviewees, for example, were hesitant to assert that what they were able to describe was incontestably visual, either because they were blind from birth and did not know what vision was like or because they knew they could not possibly be seeing with their physical eyes. The following comments were typical of this vein:

It wasn't visual. It's really hard to describe because it wasn't visual. It was almost like a tactile thing, except that there was no way I could have touched from up there. But it really wasn't visual because I just don't have vision any more. ... It [was] sort of a tactile memory or something. It's not really like vision is. Vision is more clear, but it's also more tied down.

I think what it was that was happening here was a bunch of synesthesia, where all these perceptions were being blended into some image in my mind, you know, the visual, the tactile, all the input that I had. I can't literally say I really saw anything, but yet I was aware of what was going on, and perceiving all that in my mind... But I don't remember detail. That's why I say I'm loath to describe it as a visual.

What I'm saying is I was more aware. I don't know if it's through sight that I was aware. ... I'm not sure. All I know is ... somehow I was aware of information or things that were going on that I wouldn't normally be able to pick up through seeing. . . . That's why I'm being very careful how I'm wording it, 'cause I'm not sure where it came from. I would say to you I have a feeling it didn't come from seeing, and yet I'm not sure.

Even Brad, whose initial testimony seemed so clear on this point, in a subsequent interview eventually qualified and clarified his earlier remarks about his memory of seeing snow on the streets outside his school:

I was quite aware of all the things that were physically mentioned in there [i.e., his earlier description]. However, whether it was seen visually through the eyes, I could not say. ... I mean, you have to remember, being born blind, I had no idea whether those images were visual. . . . It was something like a tactual sense, like I could literally feel with the fingers of my mind. But I did not remember actually touching the snow. . . The only thing I can really state about those images was that they came to me in an awareness and 
that I was aware of those images in a way I did not really understand. I could not really say that they were visual per se because I had never known anything like that before. But I could say that all my senses seemed to be very active and very much aware. I was aware.

Brad, too, seemed to be telling us now that he could not be certain his representation of the snow was in any definitive sense "visual" as such, especially since he had no real understanding of what a visual image was. Instead, as with others in our study, a complex multisensory awareness seems to have been involved, and, in a remarkable similarity with one of the respondents quoted above, Brad made an almost identical statement to hers about the tactile quality of his impression, again suggesting that this modality may be a key feature in the coding of these experiences by the blind, as it certainly is in their daily life.

Vicki as well, in recent exchanges with us, eventually clarified her previous statements concerning whether her experiences could be properly thought of as examples of pure seeing. In our interview with her on May 27, 1994, she allowed, "It was scary at first. . . . I had trouble relating things to one another, what I was seeing and perceiving versus what I had touched and known the way I had known things all my life." And in a telephone conversation the following year, on July 18, 1995, when one of us (K R.) asked her whether in her opinion it was a matter of seeing or knowing in her experience, she unhesitatingly replied, "It's both, Ken, it's both seeing and knowing."

As this kind of testimony builds, it seems more and more difficult to claim that the blind simply see what they report. Rather, it is beginning to appear it is more a matter of their knowing, through a still poorly understood mode of generalized awareness based on a variety of sensory impressions, especially tactile ones, what is happening around them. The question that immediately confronts us now, however, is as unavoidable as it is crucial: Why is it that these reports, when casually perused, nevertheless often seem to imply that the blind do see in a way akin to physical sight?

As we have already observed, however these experiences may have been coded originally, by the time we encounter them they have long come to be expressed in a particular linguistic form. And that form is a language of vision, since our ordinary language is rooted in the experiences of sighted persons and is therefore biased in favor of visual imagery. Because the blind are members of the same linguistic 
community as sighted persons, we can certainly expect that they will tend, and indeed will be virtually compelled, to phrase their experiences in a language of vision, regardless of its appropriateness to the qualities of their own personal experience.

And there is another clue from our transcripts that mitigates against an overly literal interpretation of our data on apparent vision in the blind. Examination of language usage by our respondents reveals that they tend to use vision verbs far more casually and loosely than do sighted persons, a finding that other researchers who have studied language in the blind (Cook, 1970; Rathna, 1962) have confirmed. Vicki, for example, said that she loves to "watch" television and uses phrases, such as "look at this," that clearly cannot be taken literally. Although this observation does not necessarily invalidate the testimony in our reports, it does send up another amber flag of caution when it comes to the interpretation of the narratives of our blind respondents.

In summary, what we have learned from our respondents is that although their experiences may sometimes be expressed in a language of vision, a close reading of their transcripts suggests something closer to a multifaceted synesthetic perception that seems to involve much more than an analog of physical sight. This is not to say that as part of this awareness there cannot be some sort of pictorial imagery as well; it is only to assert that this must not be taken in any simplistic way as constituting vision as we normally understand it.

\section{Eyeless Vision and Transcendental Awareness}

Even if we cannot assert that the blind see in these experiences in any straightforward way, we still have to reckon with the fact that they nevertheless have access to a kind of expanded supersensory awareness that may in itself not be explicable by normal means. Furthermore, notwithstanding the cases of indistinct and nebulous "sight" we have just reviewed, we must not overlook the ineluctable and very unequivocal claims on the part of most of our respondents that they did seem to possess a type of vision that was very keen, detailed, and even "crystal clear" at times. Even if these reports may not be analogous to retinal vision as such, they clearly represent something that must be directly addressed. Thus, it remains for us 
to grapple with the question of what these reports represent, if not vision.

To pursue this line of inquiry, the first point we must note is that the blind simply represent a kind of limit case in research dealing with alleged perceptions while in a near-death or out-of-body state. If blind persons report what they cannot possibly see, since they have no physically-mediated sight, or what they cannot know by other normal means, as seems to be so in at least some instances in our study, then we have clearly identified a phenomenon that threatens to cast a dark shadow on the house of conventional science. But it is equally plain that whenever we can show that such perceptions are physically impossible, whether with blind persons or not, the same kind of shadow appears, as indeed it already has, many times, in other research dealing with NDEs and OBEs. So to begin to focus more clearly on precisely what it is we need to explain here, let us look for a moment at a few illustrative cases one step removed from those we have considered in this report where "impossible perceptions" of great acuity are described by the poorly sighted.

One type of case that has long intrigued us is when such individuals are seemingly able to report such fine and improbably noticed features as, for example, "dust on the light fixtures" in an operating room when, from the location of their physical body at the time as well as their eyesight, such perceptions would manifestly be impossible. Here, then, are a couple of such instances from our previous research.

One of them came from a woman interviewed in the early 1980 s who was 48 years old at the time (Ring, 1984). She had had her NDE in connection with a surgical procedure in 1974 . What was especially noteworthy about her account at the outset, however, was her mention of her unusually garbed anesthesiologist. As she explained, he was a physician who often worked with children. And because he had found that his young patients often were confused by a team of similarly clad green-garmented doctors, he had taken to wearing a yellow surgical hat with magenta butterflies on it so he, at least, could easily be recognized. All this will, of course, be highly relevant to this woman's account of her experience which will now be described in her own words. She had gone into shock when she heard her physician exclaim, "This woman's dying!" At that point:

Bang, I left! The next thing I was aware of was floating on the ceiling. And seeing down there, with his hat on his head, I knew who he was because of the hat on his head [i.e., the anesthesiologist 
with the magenta butterfly cap]. . . it was so vivid. I'm very nearsighted, too, by the way, which was another one of the startling things that happened to me when I left my body. I see at fifteen feet what most people see at four hundred. . . . They were hooking me up to a machine that was behind my head. And my very first thought was, "Jesus, I can see! I can't believe it, I can see!" I could read the numbers on the machine behind my head and I was just so thrilled. And I thought, "They gave me back my glasses. . .." (Ring, 1984, p. 42)

She went on to describe further details of her operation, including how her body looked, the shaving of her belly, and various medical procedures that her surgical team were performing upon her, and then found herself looking at another object from a position high above her physical body:

From where I was looking, I could look down on this enormous fluorescent light . . . and it was so dirty on top of the light. [Could you see the top of the light fixture?] Yes, and it was filthy. And I remember thinking, "Got to tell the nurses about that." (Ring, 1984, p. 43)

One of the striking features of this case is this woman's observation that she was able to see so clearly during her NDE despite the fact that, as she averred, she was very nearsighted. In this respect, too, this woman's testimony is far from unique in our records. Another very similar story was told, for example, in a letter from an audiologist who likewise reported seeing dust on the light fixtures of the operating room where his NDE took place. This incident occurred in a Japanese hospital during the Korean war. In addition, this same man, who became interested in NDEs as a result of his own experience, also learned of another case, involving a nurse at the same hospital, which had a remarkable correspondence to his. On this point, as he wrote in his letter:

The odd thing about both of our experiences is that we are both extremely myopic, i.e., thick glasses and blind as bats 6" from our noses. And yet we were both able to describe accurately events, dials, details, expressions in our OBEs, without our glasses.

Such highly acute visual perceptions on the part of the poorly sighted are hardly limited to those who are apparently hovering above their bodies during NDEs. Other nonordinary states of consciousness, such as meditation, can also sometimes evoke them. Here is a particularly compelling example from a book by an optometrist whose uncorrected eyesight was 20/200: 
[At this time] I was meditating every day. . . . During one of these deep meditative states, I had a very profound and startling experience. Although my eyes were closed, I could suddenly see everything - the whole room and myself in it-and I couldn't tell where I saw seeing from! I wasn't seeing from my eyes or from any single point of view. I seemed to be seeing everything from everywhere. There seemed to be eyes in every cell of my body and in every particle surrounding me. I could simultaneously see from straight on, from above, from below, from behind, and so on. ... There seemed to be no observer separate from what was seen. There was simply awareness. (Liberman, 1995, p. 47)

Here we have an important clue about the nature of this kind of "seeing." It may not be limited to the kind of concentrated focus we sometimes encounter in cases of NDEs, where one's perceptual attention sometimes seems restricted to the physical body. Instead, as this account shows, one's awareness can be omnidirectional. In fact, this type of perception is sometimes reported by those having NDEs or OBEs, and it is precisely this feature that suggests that "awareness" is a more appropriate term for this experience than is "seeing," as the writer just quoted also implied. In this new context, then, consider this account from an NDEr whose experience occurred as a result of pneumonia during her second pregnancy. During this crisis, the woman was rushed to the hospital by her husband and, upon arrival, lost consciousness. Still, she was able to hear the nurses talking about her, saying that she was "dead meat." Nevertheless, she herself was elsewhere at the time. As she related her experience:

I was hovering over a stretcher in one of the emergency rooms at the hospital. I glanced down at the stretcher, knew the body wrapped in blankets was mine, and really didn't care. The room was much more interesting than my body. And what a neat perspective. I could see everything. And I do mean everything! I could see the top of the light on the ceiling, and the underside of the stretcher. I could see the tiles on the ceiling and the tiles on the floor, simultaneously. Three hundred sixty degree spherical vision. And not just spherical. Detailed! I could see every single hair and the follicle out of which it grew on the head of the nurse standing beside the stretcher. At the time I knew exactly how many hairs there were to look at. But I shifted focus. She was wearing glittery white nylons. Every single shimmer and sheen stood out in glowing detail, and once again I knew exactly how many sparkles there were.

In this narrative, we notice again not only this astonishing feature of omnidirectional awareness, but also a type of knowledge that stretches our concept of ordinary "vision" beyond the breaking point. 
Clearly, this is not simple "vision" at all as we are wont to understand it, but almost a kind of seeming omniscience that completely transcends what mere seeing could ever afford. Indeed, what we appear to have here is a distinctive state of consciousness, which we would like to call transcendental awareness. In this type of awareness, it is not of course that the eyes see anything; it is rather that the mind itself sees, but more in the sense of "understanding" or "taking in" than of visual perception as such. Or alternatively, we might say that it is not the eye that sees, but the "I."

Celia Green, in an important survey of OBEs (Green, 1968), found evidence for much the same concept as we are calling transcendental awareness among her respondents, too. To cite one brief relevant instance, she quoted one of her subjects as saying, "having no eyes, I 'saw' with whole consciousness" (Green, 1968, p. 70). Indeed, her survey is full of cases showing many of the features we have found in our study of the blind, including instances of keenly detailed perceptions, which some of her subjects, like ours, characterized as "crystal clear," saying things like, "I could see the room in great detail, even the specks of dust" (Green, 1968, p. 72). Green also reported examples of apparent sight through physical obstacles and multisensory or synesthetic experiences. Therefore, what students of OBEs tend to call extrasomatic vision seems to be identical to what we have labeled here transcendental awareness.

Still another domain of research that appears to involve this type of awareness is that of pre- and perinatal psychology. In some investigations of early childhood memories, for example, there are reports by adults of events they appeared to have witnessed prior to birth (Chamberlain, 1977; Cheek, 1986). In a popular book David Chamberlain (1988) wrote on apparent birth-related memories, he recounted a story that came from a $31 / 2$-year-old boy named Jason. Riding home one night, Jason spontaneously said that he remembered being born. He told his mother that he had heard her crying and was doing everything he could to get out. He said that it was "tight," he felt "wet," and he felt something around his neck and throat. In addition, something hurt his head and he remembered his face had been "scratched up." Jason's mother said she had "never talked to him about the birth, never," but the facts were correct. The umbilical cord had been wrapped around his neck, he had been monitored by an electrode in his scalp, and he had been pulled out by forceps. The photograph taken by the hospital showed scratches on his face (Chamberlain, 1988). 
Another girl, not quite 4, in speaking of her own birth, knew a "family secret" that had never been divulged to her. In this case, a friend of the mother and later an occasional babysitter named Cathy had been present at the birth, assisting the midwife. After the birth, the midwife had been busy and the mother had by then been helped into a bath, leaving Cathy temporarily alone with the baby. As the baby began to whimper, Cathy reflexively let the baby suck from her own breast. By the time the mother had returned, the baby was already asleep, and Cathy, feeling somewhat guilty about being the first person to nurse the child, elected to say nothing to the mother about it.

Nearly four years later, Cathy was babysitting this same child, and, just out of curiosity, happened to ask the child if she remembered being born. As Chamberlain related what Cathy later told him,

She answered, "Yes!," and proceeded to give an accurate account of who was present and their roles during labor and delivery. She described the dim light of the womb and the pressures felt during birth. Then the child leaned up close and whispered in a confidential tone, "You held me and gave me titty when I cried and Mommy wasn't there." At that, she hopped up and went off to play. Says Cathy, "Nobody can tell me babies don't remember their birth!" (Chamberlain, 1988, pp. 103-104)

Hearing such suggestive anecdotes as these, Chamberlain felt obliged to see whether he could confirm such reports through systematic research into the question. For this purpose, he eventually studied a paired set of 10 mothers and children and independently hypnotized them, asking them for details about the birth from their separate perspectives. Only mothers who could assure Chamberlain that they never shared details about the birth with their child were eligible for the study. For the purposes of evaluation, Chamberlain assumed that the report given by the mother would be at least an approximately accurate description of the circumstances of the birth against which the child's testimony could then be measured.

When comparing these independent accounts, Chamberlain found that in general the respective stories of mother and child agreed impressively, corresponding on specific points of detail in an almost uncanny fashion:

Mother and child reports were coherent with each other, contained many facts that were consistent and connected, and were appropriately similar in setting, characters, and sequences. The independent narratives dovetailed at many points like one story told from two 
points of view. . . Generally, reports validated each other in many details like time of day, locale, persons present, instruments used (suction, forceps, incubator) and type of delivery (feet or head first). Sequences of receiving bottled water, formula, or breast milk, appearance and disappearance of fathers, and moving in and out of different rooms were often consistent. ... Considering all the facts, objectively gathered birth memories appear to be genuine recollections of experience. (Chamberlain, 1988, pp. 106 and 120)

In all the areas we have mentioned-studies of NDEs, OBEs, meditation, and pre- and perinatal psychology-a single unified concept such as transcendental awareness can provide the basis for a parsimonious explanation for the entire and seemingly diverse array of "impossible perceptions" that research into these phenomena has disclosed. Furthermore this term seems more faithful to the nature of these experiences than one that emphasizes only the visual component.

Returning now to its specific application to our research, the reason we prefer to invoke the concept of transcendental awareness hinges on our previous discussion about the ubiquity of the language of vision. In effect, we argue that the blind, like other persons reporting OBEs and NDEs, have entered into a state of transcendental awareness, which confers access to a realm of knowledge not available in one's normal waking state, but then are forced, again just like others, to translate their experiences into visual metaphors. Thus, the supersensory kind of knowing that the experience provides becomes seeing when it undergoes the necessity of linguistic transformation. That is why NDErs and OBErs, including some of our blind respondents, speak as if they have seen, even though, we conclude, it is an almost unavoidable distortion required by common language usage.

Thus, in answer to our earlier question as to what these individuals experience, if not seeing, we submit that it is transcendental awareness, a distinctive state of consciousness and mode of knowing in its own right, which is operative in blind and sighted persons alike during their experiences and which now stands in need of explanation. But at least we have, we believe, finally identified the phenomenon itself that seems to underlie and make possible the claims that the blind can "see" during their NDEs and OBEs, and why it is that their apparent "vision" can sometimes be so extraordinarily detailed and fine as to be, in their mind, "perfect." Since transcendental awareness by definition must transcend the limitations of the senses, 
it is possible, at least at times, for one to have access to a state of consciousness in which, with "the doors of perception cleansed," things present themselves in true Blakean fashion, "as they are, infinite."

\section{Theories of Transcendental Awareness}

When confronted with the evidence for transcendental awareness we have presented in this paper, both from our own study and from the research of others, it is obvious that the generally accepted theories of human perception and cognition that derive from mainstream science will not, without some extraordinary extrapolations, be able to account for such findings. If, however, we turn instead to some recent theoretical developments in New Paradigm Science we can quickly discern the shape of the explanation we need to seek.

In recent years, a number of thinkers, influenced by developments in modern physics, have elaborated a variety of theories of consciousness which, despite their somewhat different basic postulates, all either predict or imply that blind persons should be able to have something like visual perception during NDEs and OBEs. In addition, all of these theories explicitly address the phenomenon of the NDE in general and also posit the existence of a state of consciousness that corresponds to what we have called here transcendental awareness. Among such formulations are Kenneth Arnette's "Theory of Essence" (Arnette, 1992, 1995a, 1995b), Larry's Dossey's "Nonlocality Theory of Consciousness" (Dossey, 1989), Amit Goswami's "Quantum Theory of Consciousness" (Goswami, 1993, 1994), Michael Talbot's "Holographic Theory of Consciousness" (Talbot, 1991), and Jenny Wade's "Holonomic Theory of Consciousness" (Wade, 1996).

As indicated, the ground philosophic assumptions of these theories vary. For instance, Arnette's position is one of explicit dualistic interactionism, Goswami's, a monistic idealism that nevertheless is able to incorporate some of the insights of dualistic theories without having to resort to dualism per se, while Wade's approach represents an uncompromising nondualism. Nevertheless, these theorists all agree about certain properties of consciousness itself, and on this basis they can serve as a kind of collective expression of the point of view we believe best articulates our own theoretical convictions. Let us examine next, then, this list of the common postulates of these theories having to do with the nature of consciousness. 
The first postulate on the nature of consciousness that these diverse theories share is that consciousness itself is primary and is the ground of all being. Goswami's statements are indicative of this position and sum it up succinctly:

all events are phenomena in consciousness. Beyond what we see as immanent reality, there is a transcendent reality; ultimately all reality is comprised of consciousness. The division of reality into transcendental and immanent is an epiphenomenon of experience. (Goswami, 1994, p. 1)

The second common postulate is that consciousness is nonlocal. What this assertion implies is that the mind, rather than being located in the individual and bounded by time (that is, birth and death) is fixed neither in time nor in space. In fact, in this view, it is not really appropriate, except as a shorthand convenience, to speak of the mind; instead there is, as our first proposition implies, only Mind. This insight, though derivative from a nonlocality position, may be stated as a separate assumption, namely, the third common postulate: that consciousness is unitive. That is, there is only one consciousness, which we call Mind, and the notion of individual minds is at bottom nothing more than a useful fiction that Dossey pointedly called "the illusion of a separate self and the sensation of an ego that possesses a separate mind" (Dossey, 1989, p. 98).

The fourth common postulate is that consciousness may and indeed must sometimes function independently of the brain. This is a key assumption, especially for understanding how the blind may become aware of something that seems like visual perception. Dossey again stated the matter concisely:

if the mind is nonlocal, it must in some sense be independent of the strictly local brain and body. ... And if the mind is nonlocal, unconfined to brains and bodies and thus not entirely dependent on the physical organism, the possibility of survival of bodily death is opened. (Dossey, 1989, p. 7)

Of course, as Dossey elsewhere pointed out and as all of the other theorists under consideration would agree, although Mind is neither confined to the brain nor a product of it, it may of course work through the brain to give us our representation of the phenomenal world. According to Goswami, our ordinary perception of time and space comes about as a result of a quantum-mechanical process whereby consciousness self-referentially "collapses" what are called "possibility waves" so as to give rise to actuality: "In the process of 
collapse, one undivided consciousness sees itself as apparently divided into dualities such as life and environment, subject and object" (A. Goswami, personal communication, 1995).

Thus, what we have here is an adumbration of a process that begins with Mind fully independent of brain becoming self-referential, that is, becoming identified with consciousness itself, and then converting this noumenal consciousness into a dualistic modality that generates the familiar phenomenal world. What we have called transcendental awareness is at least the beginning of the reversal of that process by which, even though the traces of an everyday dualism remain, the individual is enabled, however temporarily, to experience the world from a perspective independent of brain functioning and the operation of the senses. Each of these theories formally entails such a state of awareness, and specifically in blind persons, during NDEs or OBEs; we direct the interested reader to the citations we have provided in order to confirm our assertion that these New Paradigm theories are perfectly capable of elegantly subsuming our findings as derivations from their stated premises.

\section{Conclusion}

In the introduction to this paper, we alluded to an account of an NDE of a blind woman who afterward reported that she could see during her experience. At first blush, because this case was recounted by a well-known physician, we were probably inclined to take it at face value, perhaps also influenced by our desire to believe in the miraculous. Almost immediately, however, we learned that the story that had so beguiled us into entertaining such an appealing possibility was fictitious. But by the end of our inquiry, we came to understand that in this tale there resided still another paradox besides the one it seemed initially to represent: namely, that this was a story that was simultaneously true and false. Or perhaps we might better say it was a fictitious story that turned out to be true after all, just as the author all along had felt it just had to be. In this sense, at least, perhaps this author has received a measure of justification after the fact for his convictions, even if we cannot embrace, in this one instance, his penchant for prematurely converting belief into apparent fact.

Nevertheless, as we have seen, there is still another level of subtlety in this story, because although in a sense it is true, it is not 
entirely true. The story of Sarah implied that she really could see during her NDE, in the way that a sighted person might. We have shown this is an unwarranted inference. What seemed like an analog to physical sight really was not when examined closely. It is a different type of awareness altogether, which we have called transcendental awareness, that functions independently of the brain but that must necessarily be filtered through it and through the medium of language as well. Thus, by the time these episodes come to our attention, they tend to speak in the language of vision, but the actual experiences themselves seem to be something rather different altogether and are not easily captured in any language of ordinary discourse. Indeed, our work has shown the need to exercise critical discernment before taking these reports at face value. To be sure, they make good stories, in books or in tabloid headlines, as the case may be, but they are not always necessarily what they seem. They are more remarkable still.

What the blind experience is more astonishing than the claim that they have seen. Instead, they, like sighted persons who have had similar episodes, have transcended brain-based consciousness altogether and, because of that, their experiences beggar all description or convenient labels. For these we need a new language altogether, as we need new theories from a new kind of science even to begin to comprehend them. Toward this end, the study of paradoxical and utterly anomalous experiences plays a vital role in furnishing the theorists of today the data they need to fashion the science of the $21^{\text {st }}$ century. And that science of consciousness, like the new millennium itself, is surely already on the horizon.

\section{References}

Anderson, J. K. (1980). Life, death and beyond. Grand Rapids, MI: Zondervan.

Arnette, J. K. (1992). On the mind/body problem: The theory of essence. Journal of Near-Death Studies, 11, 5-18.

Arnette, J, K. (1995a). A critique of pure materialism. Unpublished masters' thesis, Colorado State University, Pueblo, CO.

Arnette, J. K. (1995b). The theory of essence. II: An electromagnetic-quantum mechanical model of interactionism. Journal of Near-Death Studies, 14, 77-99.

Audette, J. (1979). Denver cardiologist discloses findings after 18 years of near-death research. Anabiosis [East Peoria], 1(1), 1-2.

Bach-y-Rita, P. (1972). Brain mechanisms in sensory substitution. New York, NY: Academic Press.

Blackmore, S. (1993). Dying to live: Near-death experiences. Buffalo, NY: Prometheus.

Chamberlain, D. B. (1988). Babies remember birth. Los Angeles, CA: Tarcher/Putnam. 
Cheek, D. B. (1986). Prenatal and perinatal imprints: Apparent prenatal consciousness as revealed by hypnosis. Pre- and Peri-natal Psychology Journal, 1, 97-110.

Cook, T. H. (1970). The use of visual concepts by blind and sighted children. Unpublished doctoral dissertation, University of Houston, Houston, TX.

Dossey, L. (1989). Recovering the soul. New York, NY: Bantam.

Duplessis, Y. (1975). The paranormal perception of color (Parapsychological Monographs No. 16). New York, NY: Parapsychology Foundation.

Goswami, A. (1993). The self-aware universe. Los Angeles, CA: Tarcher/Putnam.

Goswami, A. (1994). Science within consciousness. Sausalito, CA: Institute of Noetic Sciences.

Green, C. (1968). Out-of-the-body experiences. New York, NY: Ballantine.

Gregory, R. L. (1966). Eye and brain. New York, NY: McGraw-Hill.

Grinberg-Zylberbaum, J. (1983). Extraocular vision. Psychoenergetics, 5, 141-158.

Grof, S. (1994). Books of the dead. New York, NY: Thames and Hudson.

Habermas, G. R., and Moreland, J. P. (1992). Immortality: The other side of death. Nashville, TN: Thomas Nelson.

Humphrey, N. (1993). A history of the mind. New York, NY: HarperCollins.

Irwin, H. J. (1987). Out-of-body experiences in the blind. Journal of Near-Death Studies, 6, 53-60.

Iverson, J. (1992). In search of the dead. San Francisco, CA: HarperSanFrancisco.

Kirtley, D. D. (1975). The psychology of blindness. Chicago, IL: Nelson-Hall.

Krishnan, V. (1983). OBEs in the congenitally blind. Vital Signs, 3(3), 13.

Kübler-Ross, E. (1983). On children and death. New York, NY: Collier/Macmillan.

Liberman, J. (1995). Take off your glasses and see. New York, NY: Crown.

Moody, R. A. (1975). Life after life. Covington, GA: Mockingbird Books.

Moody, R. A., and Perry, P. (1988). The light beyond. New York, NY: Bantam.

Rathna, N. A. (1962). Qualitative analysis of the visual terms used by the blind in their spoken language. Unpublished doctoral dissertation, Indiana University, Bloomington, IN.

Ring, K (1980). Life at death: A scientific investigation of the near-death experience. New York, NY: Coward, McCann and Geoghegan.

Ring, K. (1984). Heading toward omega: In search of the meaning of the near-death experience. New York, NY: Morrow.

Rogo, D. S. (1989). The return from silence: A study of near-death experiences. Wellingborough, England: Aquarian Press.

Romains, J. (1924). Eyeless sight: A study of extra-retinal vision and the paroptic sense. New York, NY: Putnam.

Sabom, M. B. (1982). Recollections of death: A medical investigation. New York, NY: Harper and Row.

Sacks, O. (1993, May 10). A neurologist's notebook: To see and not see. The New Yorker, pp. 59-73.

Talbot, M. (1991). The holographic universe. New York, NY: HarperCollins.

Valvo, A. (1971). Sight restoration after long term blindness. New York, NY: American Foundation for the Blind.

von Senden, M. (1960). Space and sight. New York, NY: Free Press.

Wade, J. (1996). Changes of mind: A holonomic theory of the evolution of consciousness. Albany, New York: State University of New York Press.

Weiskrantz, L. (1986). Blindsight. Oxford, England: Clarendon Press.

Wilson, I. (1987). The after death experience: The physics of the non-physical. New York, NY: Morrow.

Woodward, K L. (1976, August). There is life after death. McCalls, pp. 134-139. 